\title{
Estimativa de risco devido à ingestão de isótopos de urânio em fontes de águas minerais
}

Risk due assessment to the intake of uranium isotopes in mineral spring waters

Iara M. C. Camargo e Barbara Mazzilli

Departamento de Radioproteção Ambiental do Instituto de Pesquisas Energéticas e Nucleares da Universidade de São Paulo. São Paulo, SP - Brasil

CAMARG O, lara M. e Barbara Mazzilli, Estimativa de risco devido à ingestão de isótopos de urânio em fontes de águas minerais Rev. Saúde Pública, 32 (4): 317-20, 1998 


\title{
Estimativa de risco devido à ingestão de isótopos de urânio em fontes de águas minerais
}

\section{Risk due assessment to the intake of uranium isotopes in mineral spring waters}

\author{
Iara M. C. Camargo e Barbara Mazzilli \\ Departamento de Radioproteção Ambiental do Instituto de Pesquisas Energéticas e Nucleares da \\ Universidade de São Paulo. São Paulo, SP - Brasil
}

\begin{abstract}
Resumo
Objetivo Complementar dados de investigação anterior sobre o risco de indução de câncer devido à ingestão de ${ }^{226} \mathrm{Ra},{ }^{228} \mathrm{Ra}$ e ${ }^{222} \mathrm{Rn}$ em fontes de águas minerais de uma região de altos níveis de radioatividade natural, do Brasil. Desta forma, foi realizada a estimativa de indução de câncer devido à ingestão de ${ }^{238} \mathrm{U}$ e ${ }^{234} \mathrm{U}$ nessas mesmas águas.

Método O coeficiente de risco para os isótopos naturais de urânio foi considerado como sendo o mesmo daquele utilizado para a indução de sarcoma ósseo pelo ${ }^{226} \mathrm{Ra}$ e que a quantidade depositada no osso corresponde a 25 vezes a ingestão diária de ${ }^{226} \mathrm{Ra}$ e a 11 vezes a ingestão diária dos isótopos de urânio de meia-vida longa. Amostras de água das fontes ultilizadas pela população de Água da Prata, Estado de São Paulo, foram coletadas, num período de um ano, de forma a abranger todas as estações.

Resultados Foram encontradas concentrações variando de 2,0 a $28,4 \mathrm{mBq} / \mathrm{L}$ e de 4,7 a $143 \mathrm{~m} \mathrm{~Bq} / \mathrm{L}$ para ${ }^{238} \mathrm{U}$ e ${ }^{234} \mathrm{U}$, respectivamente. Baseando-se nessas concentrações foi estimado o risco devido à ingestão dos isótopos de urânio: um total de 0,3 casos de câncer por $10^{6}$ indivíduos expostos. Este dado indica que a ingestão crônica de urânio nas concentrações observadas nas fontes analisadas resultará em um acréscimo no número de casos de câncer fatais de $0,1 \%$.
\end{abstract}

Conclusões Se as incertezas na estimativa dos efeitos carcinogênicos forem levadas em consideração, pode-se concluir que praticamente nenhum caso de câncer ocorrerá devido à ingestão de urânio presente nas águas minerais analisadas.

Águas minerais, análise. Radioatividade. Análise de risco.

\section{Abstract}

Objective

To complement the data of a previous research concerning the evaluation of the lifetime risk of radiation-induced cancer due to the ingestion of ${ }^{226} \mathrm{Ra},{ }^{228} \mathrm{Ra}$ and ${ }^{222} \mathrm{Rn}$ in mineral spring waters from a natural highly radioactive region of Brazil. The study was performed to evaluate the lifetime risk of radiation-induced cancer due to the ingestion of ${ }^{238} U$ and ${ }^{234} U$ in the same spring waters.

Correspondência para/Correspondence to: Barbara Mazzilli - Caixa Postal 11049 - 05422-970 - São Paulo, SP - Brasil. E-mail: mazzilli@ net.ipen.br Edição subvencionada pela FAPESP (Processo n . 97/09815-2).

Recebico em 16.5.1997. Reapresentado em 26.12.1997. Aprovado em 26.1.1998. 
Method It is assumed that the risk coefficient for natural $U$ isotopes is the same as for the ${ }^{226} \mathrm{Ra}$-induced bone sarcomas and that the equilibrium for skeletal content is 25 times the daily ingestion of ${ }^{226} \mathrm{Ra}$, but 11 times the daily ingestion of longlived uranium isotopes. Waters samples were collected seasonally over a period of one year at all the spring sites used by the local population of Águas da Prata, S. Paulo State (Brazil).

Results Concentrations ranging from 2.0 to $28.4 \mathrm{mBq} / \mathrm{L}$ and from 4.7 to $143 \mathrm{mBq} / \mathrm{L}$ were observed for ${ }^{238} U$ and ${ }^{234} U$, respectively. Based upon the measured concentrations the lifetime risk due to the ingestion of uranium isotopes was estimated. A total of 0.3 uranium-induced cancers per $10^{6}$ exposed persons was predicted, suggesting that chronic ingestion of uranium at the levels observed at these springs will result in an incremental increase of fatal cancers of $0.1 \%$.

Conclusions By taking into account the uncertainties in evaluating the carcinogenic effects, it can be concluded that virtually no cancer would be expected from the ingestion of uranium in the mineral spring waters analyzed.

Mineral waters, analyses. Radioactivity. Risk assessment.

\section{INTRO DU ÇÃO}

O urânio ingerido acumula-se principalmente no osso e no rim. Devido à baixa atividade específica do urânio natural não foi possível, em experimentos com animais, verificar a indução de câncer relacionada à dose de radioatividade liberada, tendo em vista que o efeito da toxicidade química do urânio sobre o rim do animal prevalece sobre o dano radiológico, levando o animal à morte antes que ocorra a indução de câncer. Um experimento conduzido por $\mathrm{Finkel}^{3}$, usando isótopos de urânio artificial, demonstrou que as partículas alfa emitidas pelo urânio não diferem, em termos de seu potencial carcinogênico, das partículas alfa emitidas pelos radionuclídeos radônio e rádio. Considerando a ingestão de urânio em níveis ambientais, a maior parte deste elemento acumulado no esqueleto se distribui uniformemente através do volume do osso mineralizado ${ }^{6}$. Portanto, o risco de incidência de sarcoma ósseo por unidade de dose de radiação, devido ao acúmulo de urânio (meia-vida superior a 1.000 anos), pode ser considerado como sendo igual ao do radionuclídeo ${ }^{226} \mathrm{Ra}$.

A quantidade de ${ }^{226} \mathrm{Ra}$ em equilíbrio no esqueleto corresponde a 25 vezes a sua ingestão diária. Portanto, a ingestão diária de 5 pCi produzirá uma carga no esqueleto de $125 \mathrm{pCi}$ de ${ }^{226} \mathrm{Ra}^{6}$. A energia alfa média liberada pelo ${ }^{226} \mathrm{Ra}$ e seus produtos de decaimento é de cerca de $12,11 \mathrm{MeV}$ por desintegração de ${ }^{226} \mathrm{Ra}$. Para os isótopos de urânio as energias das partículas alfa podem ser consideradas como sendo aproximadamente 4,5 MeV. Fazendose um raciocínio análogo ao do ${ }^{226} \mathrm{Ra}$ para a incorporação de urânio nos ossos, pode-se afirmar que uma ingestão diária de 5 pCi de urânio implicará em uma carga no esqueleto 1 a 35 vezes maior. Uma estimativa da incorporação média do urânio nos ossos seria, portanto, de $55 \mathrm{pCi}$. Partindo dessas considerações, Mays e col. ${ }^{5}$ avaliaram o risco cumulativo decorrente da ingestão de 5 pCi de urânio por dia, assumindo que:

- A ingestão diária de 5 pCi de ${ }^{226} \mathrm{Ra}$ implica em um aumento de incidência de 9 casos de sarcoma ósseo por milhão de indivíduos expostos;

- A razão entre o acúmulo dos isótopos de urânio nos ossos e a ingestão diária desses radionuclídeos é 11 ;

- A razão entre as energias das partículas alfa emitidas pelo ${ }^{226} \mathrm{Ra}$ e seus produtos de decaimento e a energia das partículas alfa emitidas pelos isótopos de urânio é de 12,11:4,5.

De acordo com os resultados de Mays e col..$^{5}$, são previstos 1,5 casos de sarcoma ósseo induzidos pelo urânio por milhão de indivíduos expostos.

\section{MÉTO DO}

A região escolhida para o presente estudo, Águas da Prata, Estado de São Paulo, apresenta um dos maiores níveis de radioatividade natural do Brasil. Nessa região, muitas fontes de águas minerais são usadas pelos habitantes da região e de outras localidades, que acreditam em suas propriedades terapêuticas. A área de estudo já foi descrita em trabalho anterior ${ }^{4}$, no qual foi estimado o risco devido à ingestão de ${ }^{226} \mathrm{Ra},{ }^{228} \mathrm{Ra}$ and ${ }^{222} \mathrm{Rn}$ nas mesmas fontes de águas minerais.

As amostras de água foram coletadas em 9 fontes durante um período de um ano. Sempre que possível, cada 
amostra de água foi coletada em todas as estações do ano de forma a se obter resultados estatisticamente significativos. Cada amostra de água foi analisada em duplicata. $\mathrm{O}$ pH foi ajustado pela adição de ácido nítrico para evitar perdas por adsorção nos recipientes de coleta. Devido às baixas concentrações dos isótopos de urânio presentes nas águas analisadas, 10 litros de água foram coletados para cada determinação. As amostras foram concentradas e uma alíquota de uma solução de ${ }^{232} U$ foi adicionada como traçador, para se determinar o rendimento químico do procedimento analítico. A solução foi então percolada em uma resina Dowex 1x8 (100-200 mesh). O urânio adsorvido na coluna foi eluído com $\mathrm{HCl}$ diluído, a solução foi evaporada até secura e o resíduo dissolvido em $\mathrm{H}_{2} \mathrm{SO}_{4}$. A solução foi então percolada novamente em uma resina Dowex 1x8 (50-100 mesh) para separar o urânio de possíveis elementos interferentes, em particular outros radionuclídeos da série natural que são emissores alfa. O espectro alfa do urânio foi obtido por eletrodeposição e a medida da atividade por meio de um detetor de barreira de superfície, EG\&G ORTEC, modelo 576A. Mais detalhes sobre o procedimento experimental adotado podem ser encontrados em publicação anterior ${ }^{2}$. O limite inferior de detecção obtido foi de $1,1 \mathrm{mBq} / \mathrm{L}$ para ${ }^{238} \mathrm{U}$ e de $1,6 \mathrm{mBq} / \mathrm{L}$ para ${ }^{234} \mathrm{U}$. A incerteza total da determinação da concentração dos radionuclídeos para uma mesma fonte variou de $2 \%$ a $46 \%$, incluindo as incertezas decorrentes do procedimento experimental adotado e a variabilidade sazonal dos dados.

\section{RESU LTAD O S E DISCU SSÃO}

A média geométrica obtida a partir das medidas nas 9 fontes estudadas variou de 2,0 a $28,4 \mathrm{mBq} / \mathrm{L} \mathrm{e}$ de 4,7 a $143 \mathrm{mBq} / \mathrm{L}$ para ${ }^{238} \mathrm{U}$ e ${ }^{234} \mathrm{U}$, respectivamente (Tabela). A razão isotópica ${ }^{234} \mathrm{U} / 238 \mathrm{U}$ variou de 2,0 a 7,2. O risco devido à ingestão de isótopos de urânio presente nas águas das fontes analisadas foi estimado utilizando-se a média geométrica da concentração obtida em todas as fontes. O risco devido à ingestão dos isótopos de tório não foi considerado uma vez que em trabalho anterior verificouse que a concentração de tório nas fontes analisadas apresentou valores muito baixos, próximos do limite inferior de detecção do sistema de contagem $(0,2$ $\mathrm{mBq} / \mathrm{L})^{2}$. Usando-se a metodologia proposta por Mays e col. ${ }^{5}$, avaliou-se um total de 0,3 casos de câncer induzido por urânio por $10^{6}$ indivíduos expostos. A incidência natural desse tipo de câncer na região Sudeste do Brasil é 7,0x $10^{6} / \mathrm{ano}^{1}$, o que significa 455 casos por milhão de indivíduos assumindo uma expectativa de vida de 65 anos. Portanto, um excesso de $0,1 \%$ na taxa de incidência natural de câncer devido à ingestão de urânio natural pode ser esperado devido à ingestão das águas minerais analisadas.

A principal fonte de incerteza na avaliação do risco de câncer devido à ingestão de rádio é a forma da curva dose-resposta para indução de câncer ósseo. O número previsto de câncer induzido por isótopos de Ra foi baseado numa curva dose-resposta linear. Entretanto, se a curva dose-resposta verdadeira para indução de câncer devido à ingestão de rádio, em baixas doses, variar com o quadrado da dose, o risco verdadeiro será uma ordem de grandeza inferior ao valor calculado. Uma outra fonte de contribuição para a incerteza é a variabilidade dos parâmetros utilizados. Uma taxa de ingestão de água de 1,2 L/ dia foi usada, a incerteza desse valor pode variar de um fator de aproximadamente 2. A incerteza total na determinação da concentração dos radionuclídeos, incluindo as incertezas da técnica de medida e da variabilidade sazonal dos dados, também contribui com um fator de 1,5. Finalmente, poder-se-ia considerar que a previsão de casos de sarcoma ósseo

Tabela - Concentração de urânio em fontes de águas minerais de Águas da Prata,SP.

\begin{tabular}{lccccc}
\hline \multirow{2}{*}{ Fonte } & \multicolumn{2}{c}{ Concentração de ${ }^{238} \mathrm{U}(\mathrm{mBq} / \mathrm{L})$} & & \multicolumn{2}{c}{ Concentração de ${ }^{234} \mathrm{U}(\mathrm{mBq} / \mathrm{L})$} \\
\cline { 2 - 3 } \cline { 5 - 6 } & $\begin{array}{c}\text { Média } \\
\text { geométrica }\end{array}$ & $\begin{array}{c}\text { Intervalo de } \\
\text { concentração }\end{array}$ & & $\begin{array}{c}\text { Média } \\
\text { geométrica }\end{array}$ & $\begin{array}{c}\text { Intervalo de } \\
\text { concentração }\end{array}$ \\
\hline Vilela & 6,4 & $5,4-7,0$ & 16,1 & $15,6-16,6$ \\
São Bento & 3,6 & $2,6-5,0$ & 7,9 & $5,1-12,4$ \\
Prata Antiga & 6,3 & $4,9-8,1$ & 45,1 & $34,7-58,7$ \\
Prata Nova & 28,4 & $19,6-34,7$ & 143 & $93,8-177$ \\
Vitória & 4,8 & $4,7-4,9$ & 23,6 & $18,3-30,5$ \\
Prata Radioativa & 12,8 & $12,6-13,0$ & 33,0 & $21,8-50,1$ \\
Balneário & 25,2 & $21,8-29,2$ & & $92,6-146$ \\
Paiol & 2,0 & $1,6-2,4$ & 4,7 & $4,4-5,1$ \\
Platina & 4,7 & $3,7-5,9$ & & 17,0 & $16,6-17,4$ \\
\hline M édia geométrica & 7,3 & & 26,3 & \\
de todas as fontes & & & & 1,1 \\
Desvio- padrão geométrico & 0,9 & & &
\end{tabular}


induzido por $\mathrm{U}$ foi avaliada considerando-se como a melhor estimativa para a razão entre o acúmulo de U nos ossos e a ingestão diária desse radionuclídeo o valor médio 11 . Uma vez que a razão verdadeira varia de 1 a 35, a incerteza correspondente na previsão do número de sarcomas ósseos poderia variar de um fator de 3. Estas considerações sugerem que o risco verdadeiro está dentro de um intervalo duas ordens de grandeza acima ou abaixo do valor encontrado.
Portanto, nenhum caso de câncer seria esperado em consequiência da ingestão de urânio presente nas fontes de águas minerais analisadas. Se esta estimativa for comparada com o incremento de câncer fatal, de $2 \%$ e $0,5 \%$, obtido para a ingestão de rádio e radônio presentes nestas mesmas águas minerais ${ }^{4}$, pode-se concluir que o rádio ainda é o radionuclídeo mais crítico se considerarmos a ingestão crônica das fontes de águas minerais analisadas.

\section{REFERÊNCIAS}

1. BRUMINI, R. Câncer no Brasil: dados hispatológicos. Brasília. Ministério da Saúde, 1982.

2. CAMARGO, I.M.C. \& MAZZILLI, B. Determination of uranium and thorium isotopes in mineral spring waters. $J$. Radioanal. Nuclear Chem. Lett., 212: 251-8, 1996.

3. FINKEL, M.P. Relative biological effectiveness of radium and other alpha emitters in CF n. 1 female mice. Proc. Soc. Exptl. Biol. Med., 83: 494-8, 1953.
4. JACOMINO, V.et al. Estimates of cancer mortality due to the ingestion of mineral spring waters from a highly natural radioactive regions of Brazil J. Environ. Radioact., 33: 31929, 1996.

5. MAYS, C.W. et al. Cancer risk from the lifetime intake of $\mathrm{Ra}$ and U isotopes. Health Phys., 48: 635-47, 1985.

6. WRENN, M.E. et al. Uranium and radium metabolism Health Phys., 48: 601-33,1985. 